\title{
Analysing University Students' Quality Perceptions and Identifying Strategies in Mapping a Way Forward to Closing the Quality Gaps
}

\section{Vannie Naidoo}

\begin{abstract}
Every year universities vie for the same top students nationally and internationally. In order for a student to choose that university, the university needs to set itself apart from all the others. It can do this quiet strategically by providing top quality services. Thus service quality to a student can mean many things, namely, by the university being a world ranked tertiary institution of learning, by it having a well established faculty, by the institution having well recognised and highly skilled academics and efficient administration staff that have the students best interests at heart. All these are but a few distinguishing characteristics of high quality services that can set a university apart from others. This paper provides a review of service quality with specific reference to service quality at universities. The SERVQUAL instrument was used to measure students' perceptions on service quality at the university of KwaZulu-Natal in South Africa. The Gaps model also formed the foundation for this research study. The survey conducted on the students at the university indicated that students were dissatisfied with the services provided by the university. From the empirical results the researcher provided strategies to the university's management that could close these quality gaps and improve the service offerings made to students.
\end{abstract}

Keywords: service quality, SERVQUAL instrument, GAPS model 


\section{Introduction}

Given the financial and resource constraints under which a university operates, it is essential that when they embark on their strategic initiatives to attract students they need to understand student perceptions. From a strategic perspective, universities all over the world are becoming more aware of the need for quality. According to studies conducted by Aldridge and Rowley, (2001) and Oldfield and Baron (2000), measuring service quality within higher education is happening at universities throughout the world and is seen as a common phenomenon. This paper is based on the research survey conducted on students at the University of KwaZulu-Natal, which is ranked as one of the leading universities in South Africa. In the literature review the researcher expands briefly on defining service quality, the debate surrounding service quality within tertiary institutions, and the SERVQUAL and the GAP's model is outlined as the study is based on these two models. The researcher then identifies and analyses student's perceptions and expectations of the service offerings made by the university. Thereafter quality gaps that occur are highlighted and strategies for the university management to close these gaps are suggested as a way forward.

\section{Literature Review \\ Defining Service Quality}

Service quality or 'quality' is an abstract concept that is often difficult to define and quantify because it is context specific and means different things to different people. Before embarking on the definition of service quality it is important to describe the difference between a product and a service. According to Hoffman (2006: 28-46), four of the unique characteristics that distinguish goods from services are services intangibility, inseparability, heterogeneity and perishability. Zeithmal et al., (2009: 6) indicates that the broad definition of services implies that intangibility is a key determinant of whether an offering is a service. Services tend to be more intangible than manufactured products and manufactured products tend to be more tangible than services. Hoffman (2006: 28) argues that of the four unique characteristics that distinguish goods from services, intangibility is the primary source from which the other three characteristics emerge. Services are performances rather than objects. As a result of their intangibility, services cannot be seen, felt, 


\section{Vannie Naidoo}

tasted, or touched in the same manner as physical goods. Hoffman (2006: 28) adds that inseparability of production and consumption refers to the fact that goods are first produced, sold and then consumed, whilst services are sold first and then produced and consumed simultaneously. Heterogeneity, another characteristic of a service refers to the potential for service performance to vary from one service transaction to the next. Services are produced by people; consequently variability is inherent in the production process. Finally, perishability means that services cannot be saved; unused capacity in services cannot be reserved, and services themselves cannot be inventoried.

According to (Mangold \& Babakus, 1991: 60) the following are various definitions of service quality:

- 'Quality is a consumer-generated comparative judgement, since individuals have no implicit sense of quality unless a standard of comparison is provided' (Oliver 1997: 163).

- Service quality is 'the extent in which the service, the service process and the service organization can satisfy the expectations of the user' (Kasper, van Helsdingen \&de Vries 1999: 188).

- 'Perceived service quality is the result of the consumer's comparison of expected service with perceived service' (Bojanic 1991:29).

- Service quality is 'the outcome of a process in which consumer's expectations for the service are compared with their perceptions of the service actually delivered'.

The concept of service quality therefore has different meanings and this creates debate surrounding the area of service quality research. From a strategic perspective, these variations in meanings that stakeholders of universities have towards service quality often make it difficult for the universities management to incorporate quality in its strategy and corporate culture in a holistic and synergistic manner.

\section{The Debate Surrounding Service Quality within Tertiary Institutions}

Tertiary institutions are being forced to re-look at themselves and account for quality of education that they provide. They can do this by taking the needs of 
the students into account and having proper systems and personnel in place to implement and deliver quality service. The researcher is in agreement with Souter (1996: 72) who states that there are a number of problems in developing performance indicators within tertiary education. A particular problem is that such performance indicators tend to become measures of activity rather than true measures of quality of students' educational services.

Harvey and Green (1993:3) indicate that: 'quality can be viewed as exceptional, as perfection (or consistency), as fitness for purpose, as value for money and as transformative.' The researcher is in agreement with the above perspective. In the case of the University of KwaZulu-Natal if students perceived its' service quality in terms of exceptional service offerings, embodying academic excellence, high standards within its academic programmes and research output, a well ranked academic institution with a reputable image, then the quality concept of the way students view the institution would be enhanced.

Parasuraman, Berry and Zeithmal (1986) were one of the pioneering researchers that conducted extensive studies on measuring customer satisfaction by measuring quality. According to Hoffman and Bateman (2006:28) service quality was primarily different from product quality due to its' intangibly nature. Parasuraman et al., developed the SERVQUAL model to test quality dimensions in services. Since tertiary institutions are also provides of a service there is therefore substantial reasoning in evaluating the performance of tertiary institutions using the SERVQUAL model.

Naidoo (2011: 526) developed the following constructs that constitute quality within a tertiary institution. They are as follows:

- Quality in terms of well skilled academic staff;

- Quality of programme offering and its value and relevance to the labour market;

- Quality in terms of good facilities, equipment and lecture and recreational venues;

- Quality in terms of good administration staff who are efficient in admin and student affairs;

- Quality in terms of safety of the students at campus;

- Quality in terms of research output;

- Quality in terms of scholarships and funding facilities available to 


\section{Vannie Naidoo}

students within the campus;

- Ranking of the University within the country; and

- Global recognition of the University and the Universities commitment to international student enrolments.

Yeo (2008: 153) highlighted some ways that tertiary institutions fell short of improving service standards. He commented that not knowing what customers expect was one of the ways they failed to improve quality. Universities fail to be prepared for the shifting needs of their customers (students) in providing courses and programmes that are relevant in subject matter and teaching approaches. Often, learning processes are compromised and academic rigor is questioned. Yeo (2008: 153-154) also regarded inadequate service quality standards put in place by university management as a contributing factor to poor service quality. Institutions fail to grapple with the shortage of teaching staff when they constantly have to face the pressure of meeting increased environments to remain competitive. As such class sizes are large, thereby stretching the instructor - student ratio. The consequence is a negative effect on the level of individual attention given to each student inside and outside class.

Service performance inconsistencies are another area that has lead to service quality being lowered within universities. The institution fails to identify appropriate specifications that would meet customer expectations in terms of content, delivery, and application. Learning experience and orientation at large cannot entirely be evaluated by grades alone. Service performance should go beyond tangible forms, (Yeo 2008: 153).

Bennett et al. (2003: 141) indicates the following factors contributing to pre-purchase and post-purchase value when choosing a university course. Pre-purchase value variables that a student is likely to consider would include reputation of university; quality of staff; cost; location and distance from home; availability of desired degree (e.g. Masters of Electronic Commerce); length of course; where friends are going to study; social clubs; and social life. Postpurchase value variables that a student would consider before making the decision to study the course would be knowledge gained; quality of staff; cost; other students (motivation, friendships, quality of students); library, internet and computer access; length of course time; industry links; and social clubs; and social life. Shanker (2002: 571) argued that in a survey conducted on management students at Indian universities, the results revealed that students choosing between institutions were based on: reputation of university; number 
of applicants keen to enrol in the course; past success rate for placement; faculty expertise; width of specialisation offered; infrastructural facilities; and fees.

Another important consideration when looking at quality within tertiary institutions is the importance of support staff services to students. Zemke and Schaff (2003: 7 - 8) argued that support services amplified the role of learning by distributing tasks and experiences in several possible ways: administration services through helping students manage their non-academic responsibilities; social services through helping them increase their network via student clubs and events; and psychological services through the provision of counselling and couching support. Support services are an extension of student experiences and serves as a platform for personal growth and development. Yeo (2009: 62 - 76) stated that a similar study to the one he carried out at the Engineering Faculty in Singapore University was also carried out by Clark and Rasay (1990) where it was reported that high achieving university students were found to have made extensive use of support services.

The importance of service quality to an organization cannot be underestimated as it lies at the very core of an organizations marketing and management strategy. Students' satisfaction in their learning experience is crucial to the institutions popularity and competitive edge over other institutions. Students become the mouthpiece of institutions as they appear in promotional materials to increase experiential visibility and institutional solidarity. In this instance, they serve as customers endorsing product and service quality offered by the institutions they represent.

\section{The SERVQUAL Instrument Used to Measure Quality}

The SERVQUAL scale identifies and tests the five dimensions of quality, namely; Tangibles, Reliability, Responsiveness, Empathy and Assurance. Parasuram et al. (1985:41-45) illustrated the following:

- Tangibles are the physical facilities, equipment and appearance of staff

- Reliability refers to the firm's ability to deliver a promised service dependably and accurately

- Responsiveness refers to the service provider's willingness to help customers and provide prompt service 


\section{Vannie Naidoo}

- Assurance refers to the knowledge and courtesy of employees and their ability to inspire trust and confidence

- Empathy is demonstrated by giving caring, individualised attention.

This study used the SERVQUAL instrument to measure students' quality perceptions of the university's service offerings.

\section{The Gaps Model that Identifies Quality Gaps}

The foundation of this study is also based on the GAPS model. Zeithmal, Berry and Parasuraman developed the GAPS model (1984-1986) that is used in conjunction with the SERVQUAL instrument. This model identified four potential gaps within the service organization. According to Metters (2006: 185) Parasuraman and colleges (1985) conducted studies in several industry sectors to develop and refine SERVQUAL, a multi-item instrument to quantify customers' global (as opposed to transaction- specific) assessment of a company's service quality. Their model is commonly known as the GAPS model. Their scale involved expectations -perceptions gaps scores along five dimensions: reliability, responsiveness, assurance, empathy and tangibles. When Zeithmal, Parasuraman, and Berry asked more than 1,900 customers of five nationally known companies to allocate 100 points across the five service quality dimensions, they averaged as follows: reliability $32 \%$, responsiveness $22 \%$, assurance $19 \%$, empathy $16 \%$, and tangibles $11 \%$. Though customers consistently reported that their most important quality dimension was reliability, this area seems to be where many service companies failed. The SERVQUAL model conceptualized service quality on the basis of the differences between customer's expectations with respect to the five dimensions and their perceptions of what was actually delivered.

When a difference exists, it is characterized as a 'gap'. The model was fashioned after remarkably consistent patterns emerged from the study's interviews. Though some perceptions about service quality were specific to the industries selected, commonalities among the industries prevailed. The commonalities suggested that a general model of service could be developed. The most important insight obtained from analysing the responses was that 'a set of key discrepancies or gaps' existed regarding perceptions of service quality and the tasks associated with service delivery to customers. 


\section{Study Methodology}

A survey was conducted on students at the University of KwaZulu-Natal using a self-administered questionnaire. The survey was designed to collect information from students on their perceptions on service quality within the University of KwaZulu-Natal. The survey was conducted on students at all five campuses of the University of KwaZulu-Natal, namely, Westville, Nelson Mandela Medical School, Howard College, Pietermaritzburg and Edgewood College campuses.

Questionnaire design had important implications on the study and the researcher opted to use a five point LIKERT Scale for the questionnaire. Closed-ended questions were structured. The questionnaire used in the study was adapted to the quality dimensions peculiar to tertiary education environment and adapted to the SERVQUAL instrument developed by Parasuraman et al., (1985). Hittman (1993:77-80) suggests further that the SERVQUAL model would seem rational to use as it not only evaluates the teaching component of a tertiary institution, but also includes aspects of the total service environment as experienced by the student.

Convenience sampling technique was employed by the researcher. The researcher visited some lecture halls after gaining the permission of the respective lecturer, and conducted the survey. The researcher also employed research assistants to issue the survey out to students who frequented the library, computer LANs, and the cafeteria and student residence within all five of the University of KwaZulu-Natal campuses.

Zikmund (2000: 351) also illustrates that researchers use convenience samples to administer a large number of completed questionnaires quickly and economically. The user of research that is based on a convenience sample should remember that projecting the results beyond the specific sample is inappropriate. For the study convenient sampling was used to administer a large number of completed questionnaires quickly and economically. Generalizations will not be made with other universities, as the results are only specific to the UKZN staff and students.

The population size for the study is 40000 students (UKZN's Strategy Plan 2007). In terms of sample size, the sample included 380 students from the Westville, Howard, Edgewood, the Medical School and Pietermaritzburg campuses. These figures were arrived at using Krejcie and Morgan (1970) tables on sample size for a given population. For this study, the researcher had 


\section{Vannie Naidoo}

a $100 \%$ response rate.

The study adhered to the specific ethical guidelines by Cavana et al., (2002: 165) that the information provided by the respondent be treated as strictly confidential. A primary ethical responsibility of the researcher was guarding the privacy of the respondent.

The research variables were drawn from the literature reviewed on service quality, with specific emphasis on tertiary institutions and their related services. The questionnaire was reviewed by peers from the University of KwaZulu-Natal who were experts in research methodology, senior academics, and a professional statistician. Based on their feedback, a few questions were re-phased. In this respect, the design of the questionnaire enjoyed high content validity, and a pilot study was conducted to ensure that the instrument measured what it intended to measure.

The Cronbach's Alpha for the overall students' perceptions was 0.974 representing a good significant level of internal reliability of the measuring instrument.

\section{Research Findings}

The research findings are based on the measure of central tendency and dispersions for the service quality dimensions for the student profile. The means, standard deviations, minimum and maximum scores for the service quality dimensions for the student respondents shown in Table 1 will be discussed. Thereafter a further discussion on Table 2, which indicates the Gap scores for student respondents in the study, will follow.

In terms of perceptions of the service quality dimensions, the mean scores were ranked from highest to lowest and reveal the following: assurance $(\mathrm{m}=3.7802)$ indicating that students perceived the university as offering assurance; followed by tangibles $(m=3.6000)$ whereby students perceived the university as having a pleasant learning environment and excellent facilities; empathy (3.2479) indicating that students perceived the university as showing empathy; students perceived the university as being slightly responsive $(m=3.1289)$; and lastly students perceived the university as having a low level of reliability $(\mathrm{m}=3.1268)$.

The ranking of the variations in responses from the highest to the lowest showed the following for perceptions: responsiveness $(\mathrm{SD}=1.05590)$; 
reliability ( $\mathrm{SD}=0.98153)$; empathy $(\mathrm{SD}=0.96368)$; tangibles $(\mathrm{SD}=0.74739)$; and assurance $(\mathrm{SD}=.73658)$.

\section{Table 1: Measure of central tendency and dispersions for the service quality dimensions for the student profile}

\begin{tabular}{|l|l|l|l|l|l|}
\hline Student respondents & $\mathrm{N}$ & Min. & Max. & Mean & Std. Dev. \\
\hline Tangibles expectation & 380 & 2.33 & 5.00 & 4.3881 & .54348 \\
\hline Reliability expectation & 380 & 1.40 & 5.00 & 4.2637 & .77128 \\
\hline Responsiveness expect. & 380 & 1.00 & 5.00 & 4.3783 & .71901 \\
\hline Empathy expectation & 380 & 1.60 & 5.00 & 4.2821 & .73466 \\
\hline Assurance expectation & 380 & 2.13 & 5.00 & 4.6300 & .58950 \\
\hline Tangibles perception & 380 & 1.00 & 5.00 & 3.6000 & .74739 \\
\hline Reliability perception & 380 & 1.00 & 5.00 & 3.1268 & .98153 \\
\hline Responsiveness percept. & 380 & 1.00 & 5.00 & 3.1289 & 1.05590 \\
\hline Empathy perception & 380 & 1.00 & 5.00 & 3.2479 & .96368 \\
\hline Assurance perception & 380 & 1.47 & 5.00 & 3.7802 & .73658 \\
\hline
\end{tabular}

Whilst the highest variation was recorded for the responsiveness quality dimension, the minimum and maximum scores indicate that for all the dimensions some subjects strongly disagreed that these service quality dimensions were present; others strongly agreed (Max=5.00) for all quality dimension variables.

Regarding expectation, the mean scores ranked from highest to lowest indicated the following: students expected the university to offer more assurance $(\mathrm{m}=4.6300)$; they expected the university to offer a more attractive learning environment and better campus facilities $(\mathrm{m}=4.3881)$; they expected the university to be more responsive $(m=4.3783)$; they expected the university to be more empathetic $(\mathrm{m}=4.2821)$; and lastly they expected the university to be more reliable $(\mathrm{m}=4.2637)$.

The ranking of the variations in responses from the highest to the lowest showed the following for expectations: reliability ( $\mathrm{SD}=0.77128$ ); empathy $\quad(\mathrm{SD}=0.73466)$ responsiveness $\quad(\mathrm{SD}=0.71901) ;$ assurance $(\mathrm{SD}=0.58950)$; and tangibles $(\mathrm{SD}=.54348)$.

Whilst the highest variation was recorded for the reliability dimension, the minimum and maximum scores indicated that for all the dimensions some 


\section{Vannie Naidoo}

subjects strongly disagreed that these service quality dimensions were present; others strongly agreed $(\mathrm{Max}=5.00)$ that all quality dimensions were present.

\section{Table 2: The Gap scores for students respondents}

\begin{tabular}{|l|l|}
\hline Student respondent & Gap Scores \\
\hline Tangibles GAP score (P-E) & -0.7881 \\
\hline Reliability GAP score (P-E) & -1.1368 \\
\hline Responsiveness GAP score (P-E) & -1.2493 \\
\hline Empathy GAP score (P-E) & -1.0342 \\
\hline Assurance GAP score (P-E) & -0.8498 \\
\hline Overall GAP score (P-E) & -1.0117 \\
\hline
\end{tabular}

The Gap scores for student respondents are indicative of the difference between their respective perceptions and expectations on UKZN's service quality in respect of tangibles, reliability, responsiveness, empathy and assurance.

Table 2 illustrates that the Gap scores for the student respondents are all negative. This indicates that the student respondents' expectations far exceeded their perceptions. Therefore student were very dissatisfied with the quality of services provided by the UKZN. The highest Gap scores rated by students was responsiveness $(-1.2493)$; followed by reliability $(-1.1368)$; empathy (-1.0342); assurance (-0.8498); and tangibles (-0.7881).

\section{Strategies for Closing the Quality Gaps}

Since students in general recorded dissatisfaction in the services provided at the university. The way forward to close the quality of a gap was to improve student perceptions in the five areas of service namely tangibles, reliability, responsiveness, empathy and assurance. The researcher recommended the following strategies to university management to improve the quality gaps for students in each of the quality variables. They are put forward and discussed below as follows:

\section{Tangibles}

- Improve the layout and physical facilities at all five campuses at the UKZN. 
- Better equipment can be provided to students in the laboratories and computer centres.

- The libraries should have better facilities and better computers provided. More update books and other literacy materials should also be in place.

- The furniture in venues should be cleaned and refurbished where possible or replaced.

- The lecture venues should be clean and well lit.

- The University brochures should be more colourful and trendy so that they appeal to the student population.

- The University should have the facilities in place to cater to the needs of the disabled.

- There should be recreational and social spaces created for students at the various campuses.

- Contact personnel must at all times be neat and presentable to the students.

- Adequate parking should be provided for students' at all five campuses.

\section{Reliability}

- The University management should develop systems and procedures that standardise service production to ensure that the core service is delivered as reliably and consistently as possible.

- Before management commit to any marketing communication made to students they should ensure that the promises made in these marketing communication brochures are realistic and achievable.

- The University management must understand students changing and varying needs and wants through having up to date market research being conducted on its students on a regular basis.

- There must always be well-managed customer expectations of the reliability aspect of the service encounters and offerings made to students.

\section{Responsiveness}

- Management should implementing standard procedures to maximise 


\section{Vannie Naidoo}

responsiveness to service situations that may occur reasonably regularly.

- Management must insist that staff is trained well, so that they can respond when necessary.

- Management should develop procedure manuals to help staff respond to customer questions, complaints and requests.

- Contact staff must at all times ensure that students do not have to wait too long for assistance or to receive the service.

- Where possible management should individualise or customize the service as much as possible.

- Management must have knowledge of how the service process and outcomes are viewed by the students.

\section{Assurance}

- Management should create trust and confidence in the service encounter through the knowledge, skills and expertise of its' contact personnel.

- Creating continuity of service staff is important as it enhances student assurance levels.

- Management should create an organization-wide image that reflects the core values of the University- that being its commitment to quality teaching; research and community engagement.

- Management should build a strong corporate brand image that reflects the high quality of its service offering and the Universities commitment to research, teaching and learning.

- Management can also use cues such as employee dress, appearance of the interior and exterior of the campuses, employees' positive attitudes, visible qualifications and credentials of its staff, and pleasant campus surroundings to reassure the students and their respective parents.

- During strikes and other violent disruptions on campus, management at all times need to ensure the safety of its students.

- While students are at university management should have proper security in place to ensure that they are safe and their vehicles are safe as well. 


\section{Empathy}

Contact staff should make students feel important by responding to their needs and understanding their concerns.

Contact staff should be trained to be more empathetic towards the needs of students, especially those who coming from disadvantaged backgrounds like rural students who have very little exposure to city life. Contact staff should also be more helpful and empathetic to the disabled students who have special needs.

- Tailoring service offerings to individual student as much as possible.

- Making students feel important by developing long-term relationships with them.

- Training staff to know students by name where possible and by their related service needs.

\section{Concluding Remarks}

The study undertaken by the researcher indicated that student perceptions are crucial in the designing of strategies to close quality gaps that affect students. Student satisfaction lies at the heart of any universities competitive strategy. Therefore it is crucial that the University strive to provide quality services both in the academic and support areas. However, it all starts in understanding what students' perceptions tell us of what they perceive as quality variables. Thereafter the quality gaps that students indicate can help university management develop strategies to close the gaps and make the total service offerings made to students of the highest quality encompassing service excellence. Like any other service institution, at the end of the day, what management at a university wants, is customer satisfaction. Only through quality surveys, valuable insights into students' perceptions can be gathered, analysed and interpreted to provide valuable feedback to improve customer satisfaction by the service provider entity.

\section{References}

Alridge, S. \& J. Rowley 2001. Conducting a Withdrawal Survey. Quality in Higher Education 7,1: 55-63. 
Bennett, R., L. Bove, S. Dann, J. Drennan, L. Frazer, M. Gabbot, R. Hill, M.

Lawley, S. Matear, C. Perry, B. Sparks, J. Summers, J. Sweeney, T. Ward \& L. White 2003. Service Marketing a Managerial Approach. New Jersey: John Wiley \& Sons.

Bojanic, D.C. 1991. Quality Measurement in Professional Services Firms. Journal of Professional Services Marketing 7,2: 27-36.

Cavana, R.Y., B.L. Delahaye \& U. Sekaran 2001. Applied Business Research:

Qualitative and Quantitative Methods. New Jersey: John Wiley \& Sons.

Harvey, L. \& D. Green 1993. Defining Quality. Assessment \& Evaluation in Higher Education 18,1: 9-34.

Hittman, J.A. 1993. TQM and CQI in Post-Secondary Education. Quality Progress 26,10: 77-80.

Hoffman, K.D. \& J.E.G. Bateman 2006. Services Marketing Concepts, Strategies \& Cases. $3^{\text {rd }}$ Edition. Toronto: Thompson.

Kasper, H., P. van Helsdingen \& W. de Vries Jr. 1999. Service Marketing and Management: An International Perspective. Crichester: John Wiley \& Sons.

Mangold, W.G. \& E. Babakus 1991. Service Quality: The Front-Stage vs. the Back-Stage Perspective. Journal of Service Marketing 5,4: pp 59-70.

Metters, R., K. King-Metters, M. Pullman \& S. Walton 2006. Successful Service Operation Management. International Student Edition. Toronto: Thompson South-West.

Naidoo, V. 2011. Managerial and Economic Issues Associated with Service Quality - The Case of the University of KwaZulu-Natal. International Journal of Trade, Economics and Finance 2: 526-530.

Olfield, B.M. \& S. Baron 2000. Student Perceptions of Service Quality in a UK University Business and Management Faculty. Quality Assurance in Education 8,2:85-95.

Soutar, G. \& M. McNeil 1996 Measuring Service Quality in a Tertiary Institution. Journal of Educational Administration 34,1: 72-82.

Shanker, R. 2002. Services Marketing the Indian Perspective - Text \& Readings. New Delhi: Excel Books.

Yeo, R. 2008. Servicing Service Quality in Higher Education: Quest for Excellence. On the Horizon 16,3: 152-161.

Yeo, R.K. 2009. Service Quality Ideals in a Competitive Tertiary Environment. International Journal of Educational Research 48: 62-76.

Zeithaml, V.A., M.J. Bitner \& D.D. Gremler 2009. Services Marketing Inte- 
Student's Quality Perceptions and How to Close the Quality Gaps

grating Customer Focus Across the Firm. $5^{\text {th }}$ Edition. New York: McGraw Hill.

Zeithmal, V.A., L.L. Berry \& A. Parasuraman 1996. The Behavioural Consequences of Service Quality. Journal of Marketing 60,2: 31-46.

Zemke, R. \& D. Schaff 1989. The Service Edge. New York: Plume.

Zikmund, W.G. 2000. Business Research Methods. $6^{\text {th }}$ Edition. Fort Worth: The Dryden Press, and Harcourt College Publishers.

Vannie Naidoo

School of Management, IT and Governance University of KwaZulu-Natal Westville Campus, Durban, South Africa Naidoova@ukzn.ac.za 